\title{
Breed and season effects on the claw lesions of dairy cows in Ardebil, Iran
}

\author{
Taghi Madadzadeh ${ }^{1}$, Mohsen Nouri ${ }^{2,}$, Iradj Nowrouzian $^{3}$ \\ ${ }^{1}$ Graduated from the Faculty of Veterinary Medicine, University of Islamic Azad, Urmia, Iran \\ ${ }^{2}$ Mehregan Veterinary Group, Tehran, Iran \\ ${ }^{3}$ Department of Clinical Sciences, Faculty of Veterinary Medicine, University of Tehran, Tehran, Iran
}

Email address:

mnouri2@yahoo.com(M. Nouri)

\section{To cite this article:}

Taghi Madadzadeh, Mohsen Nouri, Iradj Nowrouzian. Breed and Season Effects on the Claw Lesions of Dairy Cows in Ardebil, Iran. Animal and Veterinary Sciences. Vol. 1, No. 6, 2013, pp. 46-50. doi: 10.11648/j.avs.20130106.11

\begin{abstract}
Seasonal and breed effects on the prevalence and type of claw lesions were investigated on 24854 cases of culled cows at central abattoir in the vicinity of Ardebil in Iran during twelve consecutive months. After recording information for each case, the feet were amputated and ground surface of the claws were pared for more morphopathological study. The prevalence rate of claw lesion among all cases was 24.2 per cent. The claws lesion in local cows $(24.4 \%)$ was more than imported Holstein cows $(22.5 \%)(\mathrm{P}<0.05)$. Most lesions occurred in the feet; the commonest were heel horn erosion (48.3\%), white line disease (25.1\%), laminitis $(12.2 \%)$, sole ulcer $(10.3 \%)$ and septic traumatic pododermatitis $(4.1 \%)$. There was a significant effect of the frequent claw lesions in each breed $(\mathrm{P}<0.05)$. Heel horn erosion was the commonest lesion in Holstein cows $(41.2 \%)$ and local cows $(49.1 \%)$ and septic traumatic pododermatitis in Holstein cows $(4.7 \%)$ and laminitis in local cows $(3.4 \%)$ were the lowest lesions. White line disease was ranked second in Holstein cows $(24.2 \%)$ and local cows $(25.1 \%)$. Significant differences were not seen between the season and claw lesions $(\mathrm{P}>0.05)$. However, data analysis also revealed that claw lesions occurred with greater frequency during the warm season in local and Holstein cows. The results obtained from this study demonstrate that lameness is an important problem in dairy herd in Ardebil. Poor management in hoof trimming, locomotion monitoring and poor quality of floors were the common causes of claw lesions.
\end{abstract}

Keywords: Breed, Cow, Claw Lesion, Lameness, Season

\section{Introduction}

Economically, lameness is one of the most important diseases of dairy cow [1-3]. On welfare grounds it is perhaps the most important disease of the modern dairy cow [4].

The temporal distribution of disease is also affected by location because of the seasonal effects of climate [5]. There is evidence of a direct correlation between the amount of rainfall and incidence of lameness in dairy cattle [6-12]. In Denmark, lameness prevalence increased after periods of high rainfall [13] but Whitaker et al. (2004) found no such relationship in UK dairy cattle [14]. In an epidemiological- study of dairy cow lameness involving 37 farms, the incidence of specific lesions associated with lameness were significantly higher in the winter time than in summer, particularly claw diseases such as heel horn erosion [15]. In New Zealand, Tranter and Morris (1991) showed that a peak incidence of lameness occurred during the winter and the late spring, its onset being associated with wet weather conditions [16]; a similar trend was reported by Jubb and Malmo (1991) [17]. In the USA, there was little difference in seasonal prevalence of lameness in milking cows, $13.7 \%$ occurring in summer and $16.7 \%$ in spring [18]. Huang et al. (1995) found that the season of highest risk for heel erosion, sole ulcer and laminitis was November and for white line separation it was July [19]. Seasonality repeated outbreaks of laminitis in dairy calves have previously been described [20]. Cook (2004) suggested that the rate of claw horn lesion development may follow a seasonal pattern with a peak in the late summer [21].

We need to better understand the relative importance of the main factors that influence the prevalence of lameness so that better preventative strategies can be developed. Evaluation of the seasonal nature of these diseases would 
thus be useful in assessing the importance of the unique risk factors for each disease. The purpose of this report was to use the abattoir database to evaluate the seasonal and breed effects on the prevalence and type of claw lesions in Ardebil dairy cattle.

\section{Materials and Methods}

This cross-sectional and descriptive study was carried out during twelve consecutive months (2005-2006) at central abattoir in the vicinity of Ardebil (Meat industrial complex) which was well equipped and with new constructions. Seasonal and breed effects on the prevalence and type of claw lesions were investigated on 24854 cases of culled cows (22327 native breed and 2527 Holstein breed). All cows were from Ardebil. During the period of investigation, 6025 culled lame cows of 24854 culled cows having claw lesions were selected for clinical and pathomorphological purpose. The five most common lesions of claw were included heel horn erosion (HHE), white line disease (WLD), sole ulcer (SU), septic traumatic pododermatitis (STP) and chronic laminitis (L) in local and imported Holstein cows in Ardebil. The owners were interviewed using a questionnaire to record information about culled lame cow. All cases aged three to eight years; both front legs and hind legs were amputated at the carpus and the tarsus, respectively, immediately after slaughter. The lower limbs of lame cows were examined after brushing and washing with water, and tabulated the type and distribution of digital lesions. The small claw lesion opened with a sharp hoof-knife to expose the entirety of the lesion or concurrent lesion and pared of the loose horn edges adjacent to the lesion. The claw lesions are then photographed by camera (model EOS-350D, Canon, Tokyo, Japan).

Statistical evaluation- All data were entered into the Statistical Analysis System (SAS Institute Inc., Cary, North Carolina). Chi-square analysis was used to test for frequency of claw lesion between local and Holstein cows and the effects of breeds and season on the claw lesions.

\section{Results}

The prevalence rate of claw lesion among all cases was 24.2 per cent (6025 lame cows with claw lesion out of 24854 cows). The claw lesion in local cows (24.4\%) was significantly $(\mathrm{P}<0.05)$ higher $(22.5 \%)$ than imported Holstein cows. 4922 cow out of 6025 cows (81.6\%) aged more than 4 years. Numbers of cases associated with claw lesion during four consecutive seasons are shown in Fig 1 for each of the five lesions.

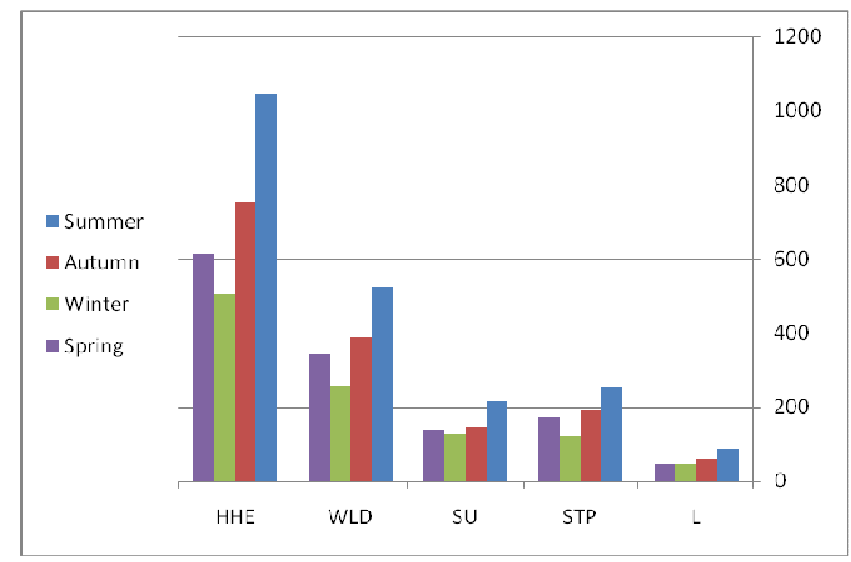

Fig 1: Numbers of lesions associated with lameness observed in Ardebil during four consecutive seasons (HHE: Heel horn erosion, WLD: White line disease, SU: Sole ulcer, STP: Septic traumatic pododermatitis, L: Laminitis).

Most lesions occurred in the feet; the commonest were heel horn erosion (48.3\%), white line disease (25.1\%), laminitis $(12.2 \%)$, sole ulcer $(10.3 \%)$ and septic traumatic pododermatitis $(4.1 \%)$, respectively. There was a significant $(\mathrm{P}<0.05)$ effect of the frequent claw lesions in each breed; Heel horn erosion was the commonest lesion in Holstein cows (41.2\%) and local cows (49.1\%) and septic traumatic pododermatitis in Holstein cows (4.7\%) and laminitis in local cows $(3.4 \%)$ were the lowest lesions. White line disease was ranked second in Holstein cows $(24.2 \%)$ and local cows $(25.1 \%)$. In the imported Holstein cows, sole ulcer and laminitis were more prevalent than local cows. In local breed, septic traumatic pododermatitis was more prevalent than imported Holstein cows.

The prevalence rate of recorded lameness was lower in winter than in summer. Significant differences were not seen between the season and claw lesion. The differences between the proportions of the most common claw lesions observed in local and imported Holstein cows are shown in Fig 2.

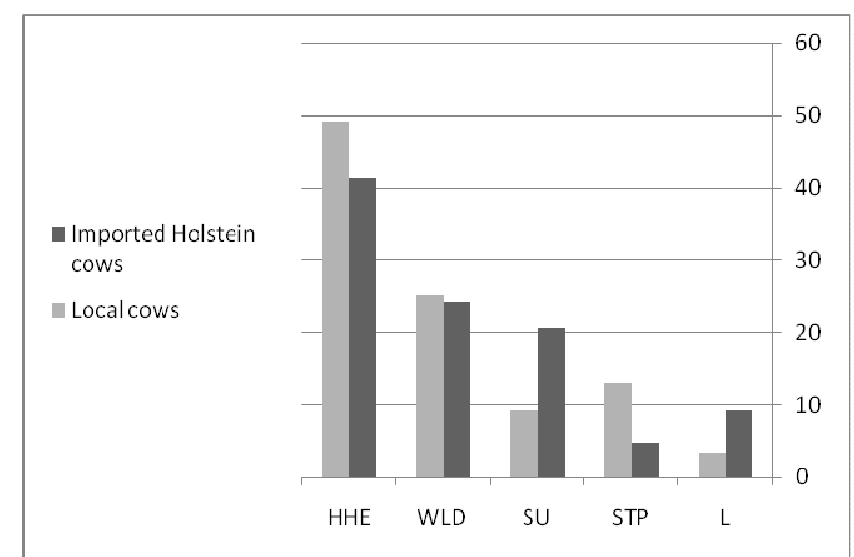

Fig 2: Percentages of front and hind feet affected by the five most common lesions of claw in local and imported Holstein cows in Ardebil during four consecutive seasons (HHE: Heel horn erosion, WLD: White line disease, SU: Sole ulcer, STP: Septic traumatic pododermatitis, L: Laminitis). 


\section{Discussion}

Lameness has now become the first largest dairy cow health challenge in the Iran; Foot lesions are most common cause of lameness in large numbers of dairy cows $[3,10$, $22,23]$.

In this study, the claws lesion in local cows $(24.4 \%)$ was more than imported Holstein cows $(22.5 \%)$. In Urmia, the prevalence rate of lameness in local cows and imported Holstein cows were $14.7 \%$ and $3.4 \%$, respectively [22]. In a survey of dairy cow lameness involving 68 farms of Marvdasht, the prevalence rate of lameness in local cows, mixed cow and imported Holstein cows were 24.6\%, $20.7 \%$ and $54.6 \%$, respectively [10]; from different types of claw lesions contributed of lameness, the most common were pododermatitis traumatic $(24.2 \%)$, sole ulcer $(18.1 \%)$ and overgrown claw (33.3\%). In Tehran, the prevalence rate of claw lesion in culling lame cows was $73.1 \%$; white line disease, toe ulcer, heel ulcer, abaxial groove lesions and sole ulcers were the most common lesions in culling lame cows $19.9 \%, 6.6 \%, 20 \%, 23.3 \%$ and $30 \%$, respectively [24]. The five most frequently recorded lesions were sole ulcer, white line disease, heel horn erosion, laminitis and punctured sole but these ranked differently in importance in different regions, possibly because of different soil and climatic factors [25].

In the present study, the pattern of the claw lesion frequency was similar in each season. This is consistent with the findings from farmers' records of 300 UK dairy herds collected between 1998 and 2002 [14], which found no effect of month or season on the number of lame cows. But data analysis also revealed that claw lesions occurred with greater frequency during the warm season in local and Holstein cows. Behavioral and physiological adaptations to periods of heat stress may be the trigger for the increase in claw lesion seen in the summer due to claw lesion development [26]. On the other hand, stored or ensiled feeds appeared to be associated with an increased prevalence of lameness. A relationship between stored feeds and lameness was suggested by Phillips (1990) [27]. Howie (1988) described a process through which low silage quality leads to reduced silage intake, reduced rumen $\mathrm{pH}$ and laminitis [28].

Field studies performed showed that the majority of lameness occurs in the rainy season [6-10, 12] and that high incidence of lameness usually follows periods of heavy rain [11]. This is in contrast to our findings that have shown a higher proportion of each common lesion occurred in the summer than winter. The lag between peaks in temperature and claw lesion development appears to be around 2 month similar to the time taken for lesions at sole corium to appear at sole surface $[15,16,26]$. Behavioral and physiological adaptations to periods of heat stress may be the trigger for the increase in lameness seen in the summer due to claw horn lesion development [26].

Heel horn erosion (HHE) and white line disease (WLD) were the predominant diagnoses in both breeds. HHE is widespread in winter-housed cattle with unhygienic conditions when feet are kept wet and rarely causes lameness unless there is extensive underrunning of the heel and sole to the depth of the corium $[15,16,29]$. It is also more frequent in older cows [16]. HHE was most common in northwest Iran (48.3 per cent) and least common in south Iran, where Meimandi and Eskandari (1996) found a proportion 3.8 per cent [10]. In a study of the hind feet of 4896 cows in France at the end of the winter housing period, Philpot et al. (1990) reported 55\% of animals affected [30]. Russell et al. (1982) reported that HHE was responsible for $8 \%$ of all lesions causing lameness in a British survey [25]. Moisture may contribute to an infection and to the persistence of superficial wounds, as well as predisposing cows to horn erosion, underrun sole and white line disease [29]. Wet concrete is 83 per cent more abrasive to the bovine hoof than dry concrete [31].

WLD was the commonest lesion in this study, which also confirms the results of Eddy and Scott (1980) [6]. It is stated that the underlying etiologies of WLD and SU are very similar, with both resulting from subclinical laminitis [32-34]. For WLD, previous reports have shown seasonality, with significantly more cases reported in winter than summer $[15,35]$. The abattoir data show seasonality, but they suggest that WLD is a disease of the summer, not winter. This change in seasonality indicates that there may have been a change in the underlying risk factors associated with the development of WLD. The abattoir data suggest that the etiology of many cases of WLD is similar to that seen in New Zealand, where WLD is by far the most common cause of lameness [36]; that is, the underlying cause of the rise in WLD is poor management of cows while herding them for milking and walking them to the parlor. Further research is require to establish whether this suggestion is correct.

A diagnosis of laminitis was made between 11.5 to 12.4 per cent of all the cases. The reason for low percent is only animals with signs of chronic laminitis were identified in this study. The prevalence of laminitis is higher in primiparous than multiparous cows, especially in autumn with clinical cases between 30 and 100 days of lactation [37]. The effect of calving pattern on seasonal lameness incidence was ignored in this analysis as the calving distributions of the cows were not known.

Sole ulcer and laminitis were more prevalent in the imported Holstein cows. It is interesting that cows housed winter in cowsheds or cubicles with concrete yards remained susceptible to this condition in the summer, whereas cows which were at pasture for most of the year were virtually free of the disease [7]. Murray et al. (1996) reported that over $60 \%$ of cases of WLD and SU occurred during the winter (November to April) [15]; in contrast, only $24.1 \%$ and $12.1 \%$ of abattoir reports occurred during this period.

The highest recorded prevalence of STP was in local breed. Particular lesion types showed a specific cow distribution and were prevalent at specific breeds, 
suggesting that a number of animal and/or environmental factors strongly predispose to lesion development. Local cows in cowsheds were more prone to STP than those in other buildings, presumably because their floors were older and rougher. These lesions appear to result from traumatic injury and bruising of the solar corium [16]. The high lesion rate in feet is probably caused partly by the direct contact of feet with environments which are often unsuitable, i.e. hard, stony, wet or contaminated with faeces, and partly by the recent emphasis on the conformation of legs rather than feet in selecting bulls and cows for breeding [7, 25]. Continued improvements in housing and flooring are essential to reduce the impact of these management changes.

Foot disease has a multifactorial origin [12]. The increase in lameness is due to a combination of physiological, behavioral, housing and environmental factors associated with heat stress and heat stress abatement procedures [38]. The distinct interactions among these risk factors plus the effect of the season and the level of humidity will determine the impact of lameness in the herd [12].

The results obtained from this study demonstrate that lameness is an important problem in dairy herd in Ardebil. Poor management in hoof trimming, locomotion monitoring and poor quality of floors (shape, hardness, friction and hygiene) were the common causes of claw lesions.

\section{Acknowledgments}

The slaughterhouse staff is acknowledged for their assistance in the preparation of abattoir specimen. The authors are particularly indebted to Dr. Raouf Alaei (the Chief meat inspector in Meat industrial complex, Ardebil) for supporting this work.

\section{References}

[1] Bruijnis MRN, Hogeveen H, Stassen EN. Assessing economic consequences of foot disorders in dairy cattle using a dynamic stochastic simulation model. J Dairy Sci. 2010; 93: 2419-32.

[2] Ettema J, Østergaard SR, Kristensen AR. Modelling the economic impact of three lameness causing diseases using herd and cow level evidence. Prev Vet Med. 2010; 95: 6473.

[3] Nouri M, Nowrouzian I, Vajhi A, Marjanmehr SH, Faskhoudi D. Morphometric radiographic findings of the digital region in culling lame cows, Asian J Anim Sci. 2011; 5:256-267.

[4] Whay HR, Main DC, Green LE, Webster AJ. Assessment of the welfare of dairy cattle using animal-based measurements: Direct observations and investigation of farm records. Vet Rec. 2003; 153:197-202.

[5] Thrusfield M. Veterinary epidemiology, 3 edition, Blackwell, $2005 ; 88-9$
[6] Eddy RG and Scott CP. Some observations on the incidence of lameness in dairy cattle in Somerset. Vet Rec. 1980; 106: 140-144.

[7] Rowlands GJ, Russell AM, Williams LA. Effects of season, herd size, management system and veterinary practice on the lameness incidence) dairy cattle. Vet Rec. 1983; 113: 441445 .

[8] Williams LA, Rowland GJ, Russell AM. Effect of wet weather on lameness in dairy cattle. Vet Rec. 1986; 118: 259-261.

[9] Haris DJ, Hibburt CD, Anderson GA, Younis PJ, Fitspatrick DH, Dunn AC, Parsons IW, McBeath NR. The incidence, cost and factors associated with foot lameness in dairy cattle in south-western Victoria. Aust Vet J. 1988; 68: 171-176.

[10] Meimandi-Parizi A and Eskandari A. Prevalence of lameness in dairy and beef cattle of Marvdasht area during the winter. Vet J. 1996; 35:115-119.

[11] Vermunt J. Herd lameness-a review, major causal factors, and guidelines for prevention and control. Proceeding of the $13^{\text {th }}$ International Symposium on Lameness in Ruminants. Maribor, Slovenia, 2004; 3-18.

[12] Ramos JM and Freire A. Effect of the year, season and animal category on the incidence of lame cows under grazing conditions in Uruguay, Proceeding of the $14^{\text {th }}$ International Symposium on Lameness in Ruminants, Clonia del Sacromente, Uruguay, 2006; 78-9.

[13] Monard J, Kassuku AA, Nansen P, Willeberg P. An epidemiological study of foot rot in pastured cattle. Acta Vet. Scand. 1983; 24: 403-417.

[14] Whitaker DA, Macrae AI, Burrough E. Disposal and disease rates in British dairy herds between April 1998 and March 2002. Vet Rec. 2004; 155:43-47.

[15] Murray RD, Downham DY, Clarkson MJ, Faull WB, Hughes JW, Manson FJ, Merritt JB, Russell WB, Sutherst JE, Ward WR. Epidemiology of lameness in dairy cattle: description and analysis of foot lesions. Vet Rec. 1996; 138: 586-591.

[16] Tranter WP, Morris RS, Williams NB. A longitudinal study of the hooves of non-lame cows. New Zealand Vet J. 1991; 39: 53-57.

[17] Jubb TF and Malmo J. Lesions causing lameness requiring veterinary treatment in pasture-fed dairy cows in East Gippsland. Aust Vet J. 1991; 68: 21-24.

[18] Wells SJ, Trent AM, Marsh WE. Individual cow risk factors for clinical lameness in lactating dairy cows. Prev Vet Med. 1993; 17: 95-109.

[19] Huang YC, Shanks RD, McCoy P. Evaluation of fixed factors affecting hoof health. Livest Prod Sci. 1995; 44: 15124.

[20] Bargai U, Shamir I, Lublin A, Bogin E. Winter outbreaks of laminitis in dairy calves: aetiology and laboratory, radiological and pathological findings. Vet Rec. 1992; 131: 411-414.

[21] Cook KB. 2004. lameness treatment rates in Wisconsin dairy herds. Proceeding of the $13^{\text {th }}$ International Symposium on Lameness in Ruminants, Maribor, Slovenia. 2004; 50-1.

[22] AziziMahmoudjigh S, DalirNaghadeh B, Ahmadian K. 
Clinical Study of lameness associated with digital disease in dairy cows in Urmia. J Vet Res. 2005; 60: 241-245.

[23] Nouri M. Occurrence of vertical fissure (sand crack) in a Holstein heifer: a case report, Asian J Anim Vet Adv. 2012; 7: $915-920$

[24] Nouri M, Marjanmehr SH, Nowrouzian I, Vajhi A, Faskhoudi D. morphopathological study of claw capsule in culling lame cows. J Vet Res. 2010; 65:157-161.

[25] Russell AM, Rowlands GJ, Shaw SR, Weaver AD. Survey of lameness in British dairy cattle. Vet Rec. 1982; 111: 155160.

[26] Cook KB, Banks RJ, Bennett TB, Bargai K. Season associated changes in infectious and claw horn lesions in a free stall housed dairy herd, Proceeding of the $14^{\text {th }}$ International Symposium on Lameness in Ruminants, Clonia del Sacromente, Uruguay, 2006; 163.

[27] Phillips CJC. Adverse effects on reproductive performance and lameness of feeding grazing dairy cows partially on silage indoors, J. Agr. Sci. 1990; 115: 253-258.

[28] Howie NM. Silage and Health. Edi., B. A. Stark. JM. Wilkinson. Proceedings of a conference, October 5, Bristol, UK Marlow, Chalcombe Publication. 1988; 23-7.

[29] Baggoit DG, Russell AM. Lameness in cattle. Brit Vet J. 1981; 137:113-32.

[30] Philipot JM, Pluvinage P, Cimarosti, Luquet F. On indicators of laminitis and heel erosion in dairy cattle: A research based on the observation of digital lesions, in the course of an ecopathological survey. Proceeding of the VIth International Symposium Disorders of Ruminant Digit, Liverpool. 1990; 184-98.
[31] Camara S and Gravert HO. Untersuchungengen uber den klaudenabrieb bein rindern. Zuchtungskunde. 1971; 43:111.

[32] Vermunt J. Subclinical laminitis in dairy cattle, New Zealand Vet. J. 1992; 40:133-8.

[33] Ossent P and Lischer Ch. Bovine laminitis: the lesion and their pathogenesis. In pract. 1998; 415-427.

[34] Weaver AD, Steiner A, and St Jean G. Lameness. In: Bovine Surgery and Lameness. $2^{\text {nd }}$ ed. Blackwell Scientific Publications, Oxford, UK. 2005; 198-232.

[35] Rowlands GJ, Russell AM, Williams LA. Effects of stage of lactation, month, age, origin and heart girth on lameness in dairy cattle. Vet Rec. 1985; 117:576-580.

[36] Chesterton RN. Linking farm physical conditions, herd management and cow behaviour to the distribution of foot lesions causing lameness in pasture-fed dairy cattle in New Zealand. Proceeding of the $13^{\text {th }}$ International Symposium on Lameness in Ruminants, Maribor, Slovenija. 2004; 200-202.

[37] Corbellini CN. Influencia de la nutrition en las enfermedades de la produccion de las vacas lecheras en transicionlnst Nac de Tec Agrop. 2000; 54-7.

[38] Shearer JK, van Amstel SR, Benzaquenl M, Shearer LC. Effect of season on claw disorders (including thin soles) in a large dairy in the southeastern region of the USA, Proceeding of the $14^{\text {th }}$ International Symposium on Lameness in Ruminants, Clonia del Sacromente, Uruguay, 2006; 110-1. 